\title{
Interfacial Tension of PBT/SAN Blends by the Drop Retraction Method
}

\author{
Edson Noriyuki Ito , Marcelo Massayoshi Ueki ${ }^{\mathrm{b}}$, Rosario Elida Suman Bretas ${ }^{\mathrm{a}}$, Elias Hage Junior ${ }^{\text {a* }}$ \\ ${ }^{a}$ Departamento de Engenharia de Materiais - DEMa, \\ Universidade Federal de São Carlos - UFSCar, \\ Rod. Washington Luiz, Km 235, 13565-905 São Carlos - SP, Brazil \\ ${ }^{\mathrm{b}}$ Núcleo de Transformação de Plásticos, SENAI - Cimatec, Salvador - BA, Brazil
}

Received: October 4, 2007; Revised: June 11, 2008

\begin{abstract}
The aim of this work was to evaluate the interfacial tension from the poly(butylene terephtalate) and poly(styrene-co-acrylonitrile) (PBT/SAN) interface region using the drop retraction method. SAN filaments were sandwiched between two PBT films; the whole system was heated up to $240{ }^{\circ} \mathrm{C}$, in a hot stage coupled to an optical microscope. The rheological parameters of the PBT/SAN system were obtained by parallel plates rheometry. An increase of the interfacial tension with the PBT molecular weight was observed with values between 0.57 and $1.06 \mathrm{mN} / \mathrm{m}$, depending on the molecular weight. Theoretical values were calculated using the geometric-mean and harmonic-mean equations and were found to be similar to the experimental results. Viscosity measurements showed that the higher the SAN/PBT viscosity ratio, the lower the interfacial tension of these blends.
\end{abstract}

Keywords: interfacial tension, drop retraction method, PBT/SAN blends

\section{Introduction}

The development of new polymeric blends is an important and creative technological way of obtaining new applications for polymeric materials, decreasing costs and optimizing properties of the final products. Most of the polymers are immiscible during their mixture with other polymers and form multiphase systems with a variety of morphologies, like: disperse droplets, fibrils, lamellar and co-continuous structures $^{1}$. The type of blend morphology affects strongly its final properties. Therefore the morphology control is a critical factor in the optimization of the polymer blend performance. This morphology depends on the interfacial tension, among other parameters ${ }^{1}$. Favis and Willis $^{2}$ have pointed out that the morphology of immiscible polymer blends seems to be controlled by the following parameters, in order of importance: interfacial tension $>$ viscosity ratio $>$ shear stress.

Studies on toughening of PBT with other rubber modified plastics containing high amount of elastomers, like ABS and AES, have concentrated efforts on simpler systems, for a better understanding of the blend morphology establishment, due to the complexity of these multiphase systems. The adequate dispersion of both styrenic terpolymers in the PBT matrix depends strongly on the interfacial tension of the system. Usually the poly(styrene-co-acrylonitrile), SAN, matrix phase from the ABS or AES terpolymer generates the interfacial region with PBT in the PBT/ABS and PBT/AES blends. In addition, those blends have another well established interface region between the rubbery phase and the SAN phase generated by the terpolymers synthesis. Paul and his collaborators ${ }^{3,4}$ have done many studies to understand those blends performance. However, the interfacial tension for PBT/SAN has not yet been evaluated to contribute to those studies.

Thus, the main objective of this work was to measure the interfacial tension between PBT and SAN, using the drop retraction method, developed by Mo et al. ${ }^{5}$ and to compare the results with theoretical results.

\section{Interfacial Tension Theoretical Background}

The surface tension is a direct manifestation of intermolecular forces at any surface. The surface molecules of a liquid or solid material are influenced by the unpaired molecular forces due to the surface discontinuity, which leads to surface molecules having additional energy. When those molecules are in contact with surrounded air the surface tension increases as the intermolecular forces among the surface molecules increase. On the other hand, the contact of a material surface with other material different than air generates an additional energy in the interface region. The additional free energy at the interface between two phases is known as interfacial tension ${ }^{6}$. The magnitude of the interfacial tension depends on the surface tension of each contact surface.

Many authors ${ }^{7-17}$ have used theoretical predictions from empirical equations that correlate interfacial tension with surface tension. From these empirical equations, the interfacial tension $(\gamma)$ between two materials can be calculated through the harmonic mean equation (Equation 1) or through the geometric mean equation (Equation 2):

$$
\begin{aligned}
& \gamma=\gamma_{1}+\gamma_{2}-\frac{4 \gamma_{1}^{d} \gamma_{2}^{d}}{\gamma_{1}^{d}+\gamma_{2}^{d}}-\frac{4 \gamma_{1}^{p} \gamma_{2}^{p}}{\gamma_{1}^{p}+\gamma_{2}^{p}} \\
& \gamma=\gamma_{1}+\gamma_{2}-2\left(\gamma_{1}^{d} \gamma_{2}^{d}\right)^{1 / 2}-2\left(\gamma_{1}^{p} \gamma_{2}^{p}\right)^{1 / 2}
\end{aligned}
$$

where $\gamma_{1}$ is the surface tension of material 1 , that is, $\gamma_{1}=\left(\gamma_{1}^{\mathrm{d}}+\gamma_{1}^{\mathrm{p}}\right)$, $\gamma_{2}$ is the surface tension of material 2, or $\gamma_{2}=\left(\gamma_{2}^{d}+\gamma_{2}^{p}\right)$, where the superscript " $d$ " refers to the non-polar contributions (dispersion contribution) and the superscript "p" to the polar contributions to the surface tension of each material.

To estimate the interfacial tension $(\gamma)$ through Equations 1 and 2 it is necessary to know the $\operatorname{polar}\left(\gamma_{\mathrm{i}}^{p}\right)$ and the non-polar $\left(\gamma_{\mathrm{i}}^{d}\right)$ contributions to the surface tensions $\gamma_{i}$. Both surface tension contributions may be represented as fractions of $\gamma_{i}$, as can be observed in the Equation 3. The polar contribution fraction may be referred as the surface polarity $\chi_{\mathrm{i}}^{\mathrm{p}}$, while the non-polar contribution fraction is added to one. Therefore, if both surface tension and the surface polarity are known for each material, it is possible to find $\gamma_{\mathrm{i}}^{\mathrm{p}}$ and $\gamma_{\mathrm{i}}^{\mathrm{d}}$, respectively. 


$$
\chi_{i}^{p}=\frac{\gamma_{i}^{p}}{\gamma_{i}}
$$

The surface polarity has been considered independent of temperature, i. e., $\frac{d \chi_{i}^{p}}{d T}=0$

The surface tension can be easily obtained for any material through experimental measurements or can be found in the literature through specific handbooks. On the other hand, the surface polarity $\chi^{\mathrm{p}}$ can be obtained as a function of the cohesive energy density $\Delta \mathrm{E}$ or as function of the solubility parameter, as shown in Equation 4:

$$
\chi^{p}=\left(\Delta E^{p} / \Delta E\right)=\left(\delta_{p} / \delta\right)^{2}
$$

where, $\Delta \mathrm{E}^{\mathrm{p}}$ is the polar contribution to the $\Delta \mathrm{E}$ and $\delta_{\mathrm{p}}$ is the polar contribution to the overall solubility parameter $\delta$. The surface polarity values obtained from surface tension have been found to agree with those obtained from cohesive energy densities calculations for a high number of polymers ${ }^{18}$.

Hansen and Skaarup ${ }^{19}$ assumed that the cohesive energy density, $\Delta \mathrm{E}$, which is proportional to $\delta$, arises from dispersive interactions $\left(\delta_{\mathrm{d}}\right)$, permanent dipole-dipole interactions $\left(\delta_{\mathrm{p}}\right)$ and hydrogen bonding forces $\left(\delta_{\mathrm{h}}\right)$, and is obtained as shown in Equation 5:

$$
\delta^{2}=\delta_{d}^{2}+\delta_{p}^{2}+\delta_{h}^{2}
$$

Those parameters $\left(\delta_{\mathrm{i}}\right)$ are referred as Hansen parameters; however, cannot predict the overall $\delta$ with accuracy for all the materials systems. The specific interactions between groups and molecules may not be given by a simple addition rule. Even so, the estimation of the Hansen parameters can be quite useful. The Hoftyzer and van Krevelen methods ${ }^{19}$ allow estimations of those parameters by the following expressions:

$$
\delta_{d}=\sum_{i} F_{d i} / V_{\text {molar }}
$$

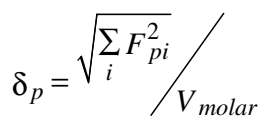

$$
\delta_{h}=\sqrt{\sum_{i} E_{h i} / V_{\text {molar }}}
$$

where $\mathrm{F}_{\mathrm{di}}$ is the dispersive force contribution, Fpi is the polar force contribution, $\mathrm{E}_{\mathrm{hi}}$ is the hydrogen bonds energy, for each chemical group of the polymer and $\mathrm{V}_{\text {molar }}$ is the molar volume. Any of the Hansen parameters can be easily calculated for any polymer if its molecular repeat unit is known. The respective values for $\mathrm{F}_{\mathrm{di}}, \mathrm{F}_{\mathrm{pi}}$ and $\mathrm{E}_{\mathrm{hi}}$ are found tabulated in specific handbooks ${ }^{19}$. The surface polarity $\chi^{\mathrm{p}}$ values for polymers determined through the use of interfacial properties have been observed to have good correlation with the ones determined using the cohesive densities ${ }^{19}$. It should be cautioned, however, that Equation 3 defines the surface polarity, while Equation 4 defines the bulk polarity. These two values may not be the same, if the polymer has sufficiently long surface-active segments, which tend to preferentially adsorb on the surfaces.

Therefore, from the above calculation procedures it is possible to estimate the the interfacial tension $(\gamma)$ between two materials of the Equations 1 and 2.
In the molten state it is very difficult to measure the interfacial tension between polymers due to their high viscosities. Therefore, numerous methods have been developed to measure this parameter, which can be classified as: thermodynamics (static), dynamics and rheological ${ }^{20}$.

The thermodynamics methods require long measurement times, due to the polymers high viscosities; therefore, there is a risk of polymer thermal degradation. The main thermodynamic methods are: the pendent droplet, the sessile droplet and the rotating droplet ${ }^{20}$.

The dynamic methods have the advantage of taking less time, thus compensating problems due to thermal perturbation. The main dynamic methods are: the breaking thread and the droplet retraction. The "breaking thread" is more complex from the experimental point of view and especially for systems were the viscosity ratio is higher than one ${ }^{20}$.

As a matter of fact there is not a preferential method for measuring the interfacial tension, because each one has its advantages and disadvantages.

In the three-dimensional deformation model, the drop shape is subsequently described by a symmetric, positive-definite, second rank tensor $\mathrm{S}$; its eigenvalues represent the square semi-axis of an ellipsoid. The evolution of this tensor results from the action of the interfacial tension and from the hydrodynamic drag exerted by the movement and can be described by an evolution model proposed by Maffettone et al. ${ }^{21}$, given by:

$$
\frac{d S}{d t}-\Omega \cdot S+S \cdot \Omega=-\frac{f_{1}}{\tau}[S-g(S) I]+f_{2}(E \cdot S+S \cdot E)
$$

where $\Omega$ is the vorticity tensor, $\mathrm{f}_{1}$ and $\mathrm{f}_{2}$ are coefficients which are functions of the viscosity ratio, $\tau$ is a characteristic time, $\mathrm{I}$ is a second order unit tensor and $\mathrm{E}$ is the deformation rate tensor.

Assuming constant droplet volume, Mo et al. ${ }^{5}$ developed an equation for the evolution of $S$ in a flow field. If $E$ and $\Omega$ are equal to zero, Equation 9 can be simplified to:

$$
\begin{aligned}
& \left(\lambda_{1}-\lambda_{2}\right)=\left(\lambda_{1}-\lambda_{2}\right)_{0} \exp \left(-f_{1} \frac{t}{\tau}\right)= \\
& \left(\lambda_{1}-\lambda_{2}\right)_{0} \times \exp \left[-\frac{\gamma}{\eta_{m} R_{0}} \frac{40(p+1)}{(2 p+3)(19 p+16)} t\right]
\end{aligned}
$$

where : $\lambda_{1}=\mathrm{L}^{2}, \lambda_{2}=\mathrm{B}^{2}$, $\mathrm{L}$ being the larger semi-axes and $\mathrm{B}$ the smaller semi-axes, $\eta_{\mathrm{m}}$ is the matrix viscosity, $p$ is the viscosity ratio $=\eta_{\mathrm{d}} / \eta_{\mathrm{m}}$, where $\eta_{d}$ is the viscosity of the disperse phase, $R_{0}$ is the equilibrium droplet radius and $t$ is the measurement time in seconds.

\section{Experimental}

\subsection{Materials}

Three different molecular weights PBT's were used in this work, named Valox 195, 325 and 315, from GE South America Plastics. The SAN, grade CN77E, was from Bayer Polymers S.A.

\subsection{Melt flow index}

Melf flow index was measured following ASTM D1238-00 standard procedure using a load of $1.20 \mathrm{~kg}$ and a temperature at $250{ }^{\circ} \mathrm{C}$.

\subsection{Molecular weight measurements}

The PBT number average molecular weight, $\overline{\mathrm{M}}_{\mathrm{n}}$ was determined by measuring the intrinsic viscosity [ $\eta]$ using an Ubbelhode viscosim- 
eter and a solvent mixture of 60/40 (weight \%) of phenol (Synth) and 1,1,2,2-tetrachloroethane (J.T. Baker).

The PBT samples were previously dried during 16 hours at $60^{\circ} \mathrm{C}$ under vacuum. PBT solutions were prepared using a concentration of $0.3 \mathrm{~g} / \mathrm{dL}$ at room temperature.

The intrinsic viscosity $[\eta]$ was measured at $30 \pm 0.1{ }^{\circ} \mathrm{C}$ using the one point method ${ }^{22,23}$ and the relationships given by Solomon and Ciuta (Equation 11), Rao and Yaseen (Equation 12) and Deb and Chatterjee (Equation 13).

$$
\begin{aligned}
& {[\eta]=(\sqrt{2} / c)\left(\eta_{s p}-1 n \eta_{r}\right)^{1 / 2}} \\
& {[\eta]=(1 / 2 c)\left(\eta_{s p}+1 n \eta_{r}\right)} \\
& {[\eta]=(1 / c)\left(31 n \eta_{r}+1,5 \eta_{s p}^{2}-3 \eta_{s p}\right)^{1 / 3}}
\end{aligned}
$$

where $\mathrm{c}=$ solution concentration, $\eta_{\mathrm{sp}}=$ specific viscosity $=\left(\eta_{\mathrm{r}}-1\right)$ and $\eta_{\mathrm{r}}=$ relative viscosity $=\eta / \eta_{\mathrm{o}}$, where $\eta$ is the measured viscosity and $\eta_{\mathrm{o}}$ is the solvent viscosity. The intrinsic viscosity [ $\left.\eta\right]$ was averaged out from values obtained through each one of the above equations. The correlation between $\bar{M}_{n}$ and [ $\eta$ ] given by Borman ${ }^{24}$ was used, as shown in Equation 14:

$$
[\eta]=1.16610^{-4} \overline{\mathrm{M}}_{n}
$$

The average molecular weight of the SAN copolymer samples was determined by gel permeation chromatography, GPC. The SAN solutions were prepared in tetrahydrofurane solvent (Vetec). The solution was filtered and injected at $40{ }^{\circ} \mathrm{C}$ at $1 \mathrm{~mL} / \mathrm{min}$ in a Waters 410 chromatograph, with a refraction index detector and Ultrastyragel columns. The calibration curves were constructed with 12 PS monodisperse standard samples from Shodex Standard.

\subsection{Determination of the amount of acrylonitrile in the SAN copolymer}

A Fisons Instruments equipment model EA 1108 CHNS-O was used to determine the concentration of nitrogen of the SAN samples.
The amount of nitrogen $(\% \mathrm{~N})$ measured was therefore used to calculate the \% of acrylonitrile in the SAN copolymer, by using the following relationship:

$$
\% \text { Acrylonitrile }_{\text {SAN }}=\frac{\% N \times 100}{26.42}
$$

\subsection{Rheological measurements}

The zero shear viscosity $\eta_{0}$ was measured in a strain controlled rheometer, ARES, from Rheometrics, at $240{ }^{\circ} \mathrm{C}$, under nitrogen atmosphere, using parallel plates with $25 \mathrm{~mm}$ diameter and gap of $1 \mathrm{~mm}$. The time for measurement of $\eta_{0}$ was similar to the time for the droplet retraction.

\subsection{Interfacial tension measurement}

Films of PBT were produced by compression molding, at $240{ }^{\circ} \mathrm{C}$, after drying the $\mathrm{PBT}$ at $60^{\circ} \mathrm{C}$, during 12 hours, under vacuum. SAN filaments were prepared after heating the polymer at $220^{\circ} \mathrm{C}$; the SAN was therefore drawn to produce filaments with $80 \sim 120 \mu \mathrm{m}$ of diameter. These filaments were set between the PBT films, forming a "sandwich" structure. This "sandwich" structure was fixed between two glass slides and the whole set was heated up to $240{ }^{\circ} \mathrm{C}$ using a hot stage THMS 600 from Linkan. To avoid thermal degradation, a nitrogen saturated atmosphere was used. The thread rupture and droplet retraction was monitored using a transmitted light optical microscope, Leica Model DM RXP and image acquisition software Image-Pro Plus. The droplet aspect ratio was thus determined.

\section{Results and Discussion}

Table 1 shows the melt flow index of the polymers and the values of number average molecular weights, $\bar{M}_{n}$, of the PBT and SAN samples obtained as received and after the interfacial tension measurements.

Table 2 shows the values of $\eta_{0}$ of the polymers, at different times. The viscosity ratio $\mathrm{p}=\eta_{\mathrm{SAN}} / \eta_{\mathrm{PBT}}$ was calculated from those

\begin{tabular}{|c|c|c|c|}
\hline Polymer & $\begin{array}{l}\text { MFI }(\mathrm{g} / 10 \mathrm{~min}) \\
250^{\circ} \mathrm{C} / 1.20 \mathrm{~kg}\end{array}$ & $\overline{\mathrm{M}}_{\mathrm{n}}(\mathrm{g} / \mathrm{mole})$ & $\begin{array}{l}\overline{\mathrm{M}}_{\mathrm{n}}(\mathrm{g} / \mathrm{mole}) \text {, after submitted to } 240{ }^{\circ} \mathrm{C} \\
\text { for different times }\end{array}$ \\
\hline PBT 20 (Valox 195) & $71.3^{(* 1)}$ & $21,300 \pm 2,400^{(* 2)}$ & $24,300 \pm 2,700^{(* 2)}(15 \mathrm{~min})$ \\
\hline PBT 30 (Valox 325) & $10.0^{(* 1)}$ & $33,600 \pm 3,800^{(* 2)}$ & $30,100 \pm 3,400^{\left(*_{2}\right)}(30 \mathrm{~min})$ \\
\hline PBT 40 (Valox 315) & $6.2^{(* 1)}$ & $41,700 \pm 4,600^{(* 2)}$ & $40,900 \pm 4,600^{(* 2)}(50 \min )$ \\
\hline SAN (CN77E) & $10.0^{(* 1)}$ & $46,900^{(* 3)}$ & $41,500^{(* 3)}(15 \mathrm{~min})$ \\
\hline$\left(75 \% \mathrm{~S} / 25 \% \mathrm{AN}^{(* 4)}\right)$ & & & $41,000^{(* 3)}(30 \mathrm{~min})$ \\
\hline
\end{tabular}
results (Table 3 ).

The PBT surface tension at $240{ }^{\circ} \mathrm{C}$ was calculated using the values of surface tension at $20^{\circ} \mathrm{C}$ and $(-\mathrm{d} \gamma / \mathrm{dT})$ of the literature ${ }^{16}$ for

Table 1. Melt flow index and number average molecular weights of the polymers.

${ }^{* 1}$ Following ASTM D1238-00 standard procedure; ${ }^{* 2}$ By solution viscosimetry; ${ }^{* 3}$ By GPC; ${ }^{* 4}$ From equation 15 .

Table 2. Zero shear viscosity, $\eta_{0}$, of the PBT and SAN samples, measured at $240{ }^{\circ} \mathrm{C}$ for different times.

\begin{tabular}{lcccc}
\hline & \multicolumn{4}{c}{$\eta_{0}($ Pa.s $)$} \\
\cline { 2 - 5 } Polymers & $\mathrm{t}=0 \mathrm{~min}$ & $\mathrm{t}=15 \mathrm{~min}$ & $\mathrm{t}=30 \mathrm{~min}$ & $\mathrm{t}=50 \mathrm{~min}$ \\
\hline SAN & 566 & 528 & 526 & 504 \\
PBT 20 & 79 & 105 & - & - \\
PBT 30 & 489 & - & 447 & - \\
PBT 40 & 1,022 & - & - & 670 \\
\hline
\end{tabular}

Table 3. The viscosity ratio, $\mathrm{p}$, of the PBT and SAN samples, measured at $240{ }^{\circ} \mathrm{C}$ for different times.

\begin{tabular}{lllll}
\hline $\mathrm{p}=\eta \mathrm{SAN} / \eta \mathrm{PBT}$ & $\mathrm{t}=0 \mathrm{~min}$ & $\mathrm{t}=15 \mathrm{~min}$ & $\mathrm{t}=30 \mathrm{~min}$ & $\mathrm{t}=50 \mathrm{~min}$ \\
\hline SAN/PBT20 & 7.16 & 5.03 & - & - \\
SAN/PBT30 & 1.16 & - & 1.18 & - \\
SAN/PBT40 & 0.55 & - & - & 0.75 \\
\hline
\end{tabular}


the poly(butylene isophthalate), due to their chemical similarity as shown in Figure 1.

The surface tension of SAN with $25 \%$ of acrylonitrile at $20^{\circ} \mathrm{C}$ was calculated by interpolation in a surface tension versus $\%$ acrylonitrile curve obtained from the literature ${ }^{16}$.

The values of density $\rho$ for both SAN and PBT, shown in Table 4, were obtained from the data file of the Moldflow MPI 4.1 software.

It was verified that the majority of the $(-\mathrm{d} \gamma / \mathrm{dT})$ values ${ }^{18}$ for polymers is in the range between 0.06 and 0.08 ; therefore due to the difficulty of calculating the SAN surface tension at $240{ }^{\circ} \mathrm{C}$, those values were used to estimate its surface tension, which is also shown in Table 5.

The value of $\chi^{\mathrm{p}}$ for the PBT was obtained from the literature ${ }^{16}$ while the value of $\chi^{\mathrm{p}}$ for the SAN copolymer was calculated from the cohesive energy density, Equation 4. The values of $\chi^{\mathrm{p}}, \gamma^{\mathrm{d}}$ and $\gamma^{\mathrm{p}}$ for the PBT and the SAN are given in Table 4.

Figure 2 shows the SAN filament breaking and drop retraction in the PBT matrix. These pictures were taken after 45 minutes at $240{ }^{\circ} \mathrm{C}$, with 30 seconds of time interval between each picture.

The change in the SAN droplet retraction dimensions, given by the difference $\lambda_{1}-\lambda_{2}$, where $\lambda_{1}=L^{2}, \lambda_{2}=B^{2}$, as in Equation 10, was measured as a function of time and it is shown in Figure 3. The average interfacial tension $(\gamma)$ was obtained from the slope of the curves at different $\mathrm{R}_{0}$, and it is shown in Table 5 .

It can be observed that the results obtained from the drop retraction experiments reasonably agree with the calculated values from the harmonic mean and the geometric mean equations.

The empirical equations are useful for calculating the interfacial tension although there is a difference between the experimental and<smiles>CCCCCCOC(=O)c1cccc(C(C)=O)c1</smiles>

(a)<smiles>CC(C)(O)c1ccc(C(=O)OCCCCO)cc1</smiles>

(b)

Figure 1. Chemical structure of: a) Poly(butylene isophthalate) and b) Poly(butylene terephthalate) (PBT). the calculated data because the calculation procedure has referred to the polymer as mer units and the experimental data make use of the polymer bulk to obtain the interfacial tension. However, there is no other data for PBT/SAN systems to compare with the experimental results and its can give an indication of the efficiency of the method. In addition, the experimental values stay between the harmonic

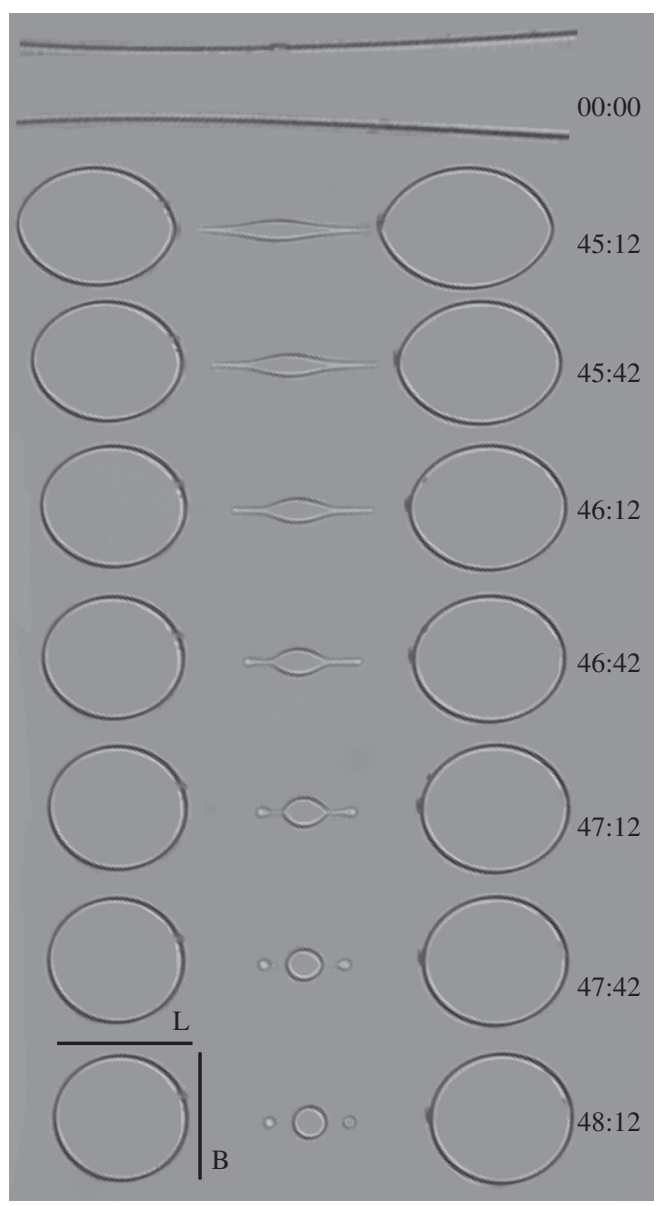

Figure 2. SAN filament break and droplet retraction in a PBT matrix after 45 minutes at $240{ }^{\circ} \mathrm{C}$, where $\mathrm{L}$ and $\mathrm{B}$ are the semi-axis of the ellipsoid drop, respectively.

Table 4. Density $(\rho)$, surface tension $(\gamma),(-\mathrm{d} \gamma / \mathrm{dT})$, surface tension components $\left(\gamma^{\mathrm{d}}, \gamma^{\mathrm{p}}\right)$ and polarity $\left(\chi^{\mathrm{p}}\right)$ for PBT and SAN, at different temperatures.

\begin{tabular}{|c|c|c|c|c|c|c|c|c|}
\hline & $\begin{array}{c}\rho\left(25^{\circ} \mathrm{C}\right) \\
\left(\mathrm{g} / \mathrm{cm}^{3}\right)\end{array}$ & $\begin{array}{c}\rho\left(240^{\circ} \mathrm{C}\right) \\
\left(\mathrm{g} / \mathrm{cm}^{3}\right)\end{array}$ & $\begin{array}{c}\gamma\left(20^{\circ} \mathrm{C}\right) \\
(\mathrm{mN} / \mathrm{m})\end{array}$ & $\begin{array}{c}-\mathrm{d} \gamma / \mathrm{dT} \\
(\mathrm{mN} / \mathrm{mK})\end{array}$ & $\begin{array}{c}\gamma\left(240^{\circ} \mathrm{C}\right) \\
(\mathrm{mN} / \mathrm{m})\end{array}$ & $\chi^{\mathrm{p}}$ & $\begin{array}{c}\gamma^{\mathrm{d}}\left(240^{\circ} \mathrm{C}\right) \\
(\mathrm{mN} / \mathrm{m})\end{array}$ & $\begin{array}{c}\gamma^{p}\left(240{ }^{\circ} \mathrm{C}\right) \\
(\mathrm{mN} / \mathrm{m})\end{array}$ \\
\hline PBT & 1.31 & 1.05 & 47.8 & 0.080 & 30.2 & 0.270 & 22.05 & 8.15 \\
\hline SAN & 1.06 & 0.96 & 41.5 & $\begin{array}{l}0.06 \\
0.07 \\
0.08\end{array}$ & $\begin{array}{l}28.3 \\
26.1 \\
23.9\end{array}$ & 0.150 & $\begin{array}{l}4.25 \\
3.92 \\
3.59\end{array}$ & $\begin{array}{l}24.05 \\
22.18 \\
20.31\end{array}$ \\
\hline
\end{tabular}

Table 5. Experimental and calculated values of the interfacial tension $(\gamma)$ of the PBT/SAN system.

\begin{tabular}{|c|c|c|c|c|c|c|c|}
\hline \multirow[t]{3}{*}{$\gamma(\mathrm{mN} / \mathrm{m})$} & \multirow[t]{3}{*}{ Experimental } & \multicolumn{3}{|c|}{ Calculated values from harmonic mean equation } & \multirow{2}{*}{\multicolumn{3}{|c|}{$\begin{array}{c}\text { Calculated values from geometric mean equation } \\
\qquad(-\mathrm{d} \gamma / \mathrm{dTSAN})\end{array}$}} \\
\hline & & \multicolumn{3}{|c|}{$(-\mathrm{d} \gamma / \mathrm{dTSAN})$} & & & \\
\hline & & 0.06 & 0.07 & 0.08 & 0.06 & 0.07 & 0.08 \\
\hline PBT20/SAN & $0.57 \pm 0.02$ & - & - & - & - & - & - \\
\hline PBT30/SAN & $0.87 \pm 0.28$ & 1.32 & 1.49 & 1.85 & 0.67 & 0.77 & 0.96 \\
\hline PBT40/SAN & $1.06 \pm 0.01$ & - & - & - & - & - & - \\
\hline
\end{tabular}




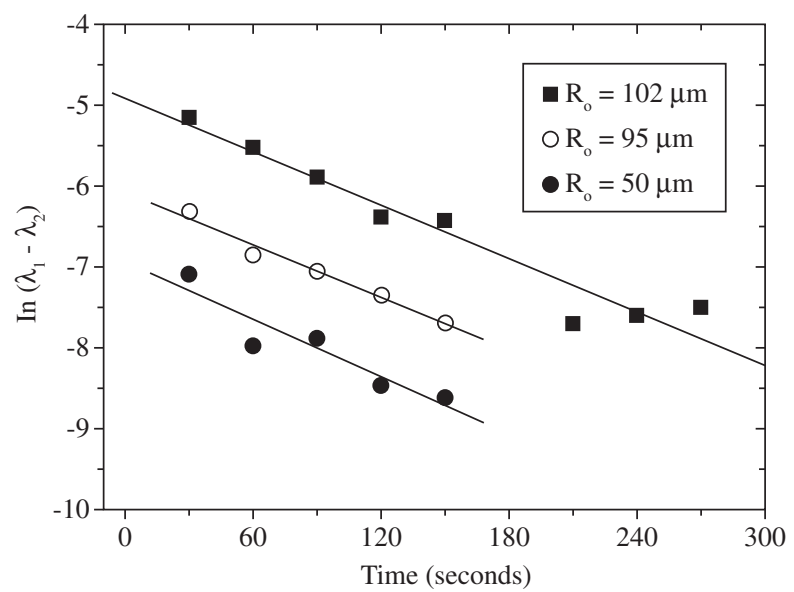

Figure 3. The change in the SAN droplet rectraction dimensions as function of the time.

and geometric means calculated values, as already shown by $\mathrm{Wu}^{16}$ in several polymer pair systems (PEO/PDMS, PVAc/PDMS, PCP/ PDMS, PCP/PnBMA, PCP/PS, PMMA/PNBMA, PMMA/PtBMA, PMA/PEHA, etc). It is also observed from Table 5 that the change in $(-\mathrm{d} \gamma / \mathrm{dT})$ from 0.06 to 0.08 does not change significantly the calculated interfacial tension values. For the PBT/SAN system, it was observed an increase in the interfacial tension as a function of the increase in the PBT molecular weight, as already observed by $\mathrm{Kamal}^{25}$ for PP/ PS systems. For that system the increase was observed up to a certain molecular weight then it leveled off for further increase.

The calculated values of the interfacial tension for PBT/PS blends were obtained by $\mathrm{Bu}$ and $\mathrm{He}^{18}$ at $250{ }^{\circ} \mathrm{C}$. They used the harmonic mean equation to obtain those values and found the interfacial tension to be equal to $1.29 \mathrm{mN} / \mathrm{m}$, which is in the same range of results for the PBT/SAN system found here.

\section{Conclusions}

The interfacial tension of the PBT/SAN system was measured at $240{ }^{\circ} \mathrm{C}$ using a modified droplet retraction method, developed by Mo et al. The experimental values have shown a reasonable agreement with the calculated ones using the harmonic and geometric averages equations. The increase in the PBT molecular weight promoted an increase in the interfacial tension for the PBT/SAN system.

\section{Acknowledgments}

This work was financially supported by the Brazilian research funding agencies CAPES, FAPESP and PRONEX(CNPq/FINEP) and GE South America Plastics and Bayer Polymers S.A. for the materials.

\section{References}

1. Paul DR, Bucknall CB. Polymer Blends. Formulation. New York: John Wiley and Sons; 2000.

2. Favis BD, Willis JM. Phase Size / Composition Dependence in Immiscible Blends: Experimental and Theoretical Considerations. J. Polym. Sci. Part B: Polym. Phys. 1990; 28(12):2259-2269.

3. Hale W, Keskkula H, Paul DR. Compatibilization of PBT/ABS blends by methyl methacrylate - glycidyl methacrylate - ethyl acrylate terpolymers. Polymer 1990; 40(2):365-377.

4. Hale W, Lee JH, Keskkula H, Paul DR. Effect of PBT melt viscosity on the morphology and mechanical properties of compatibilized and uncompatibilized blends with ABS. Polymer 1999; 40(13):3621-3629.
5. Mo H, Zhou C, Yu W. A new method to determine interfacial tension from the retraction of ellipsoidal drops. J. Non-Newtonian Fluid Mechanics 2000; 91(2-3):221-232.

6. Van Krevelen DW. Properties of Polymers. $3^{\text {rd }}$ ed. Amsterdam: Elsevier; 1990. [Chapter 7 and 8].

7. Wu S. Formation of dispersed phase in incompatible polymer blends: interfacial and rheological effects. Polym. Eng. Sci. 1987; 27(5):335-343.

8. Guo HF, Gvozdic NV, Meier DJ. Prediction and manipulation of the phase morphologies of multiphase polymer blends: II. Quaternary systems. Polymer 1997; 38(19):4915-4923.

9. Guerrica-Echevarría G, Eguiazábal JI, Nazábal J. Interfacial tension as a parameter to characterize the miscibility level of polymer blends. Polymer Testing 2000; 19(7):849-854

10. Visscher EJ, Willemse RC. Interfacial tension of polypropylene/ polystyrene: Degradation of polypropylene. Poly. Eng. Sci. 1999; 39(7):1251-1256.

11. Chapleau N, Favis BD, Carreau PJ. Measuring the interfacial tension of polymers in the presence of an interfacial modifier: migrating the modifier to the interface. J. Polym. Sci. Part B: Polym. Phys. 1998; 36(11):1947-1958.

12. Lee HS, Kim ES. Linear viscoelasticity and the measurement of interfacial tension in a partially miscible polymer mixture. Macromolecules 2005; 38(4):1196-1200.

13. Kirrjava J, Rundqvist T, Holsti-Miettinem R, Heino M, Vainio T. Determination of interfacial tension between PA/PP and LCP/PP by IFR Method and Effect of compatibilization on interfacial tension. J. Appl. Polym. Sci. 1995; 55(7):1069-1079.

14. Everaert V, Groeninckx G, Pionteck J, Favis BD, Aerts L, Moldenaers P, Mewis J. Miscible PS/PPE compounds: an alternative for blend phase morphology studies? Influence of the PPE content on the surface tension of PS/PPE and on the interfacial tension in PP/(PS/PPE) and POM/(PS/ PPE) blends. Polymer 2000; 41(3):1011-1025.

15. Son Y. Measurement of interfacial tension between polyamide- 6 and poly(styrene-co-acrilonitrile) by breaking thread method. Polymer 2001; 42(3):1287-1291.

16. Wu S. Polymer Interface and Adhesion. New York: Marcel Dekker, Inc.; 1982.

17. Bu W, He J. The effect of mixing time on the morphology of immiscible polymer blends. J.Appl. Polym. Sci. 1996; 62(9):1445-1456.

18. Wu S. Surface and interfacial tension of polymers, oligomers, plasticizers, and organic pigments. In Brandrup J, Immergut EH, Grulke EA. (Editors). Polymer Handbook. 4 ed. New York: John Wiley \& Sons; 1999. $\mathrm{VI} / 521-569$.

19. Grulke EA. Solubility parameter values. In Brandrup J, Immergut EH, Grulke EA. (Editors). Polymer Handbook. 4 ed. New York: John Wiley \& Sons; 1999 . VII/675-714.

20. Xing P, Bousmina M, Rodrigue D, Kamal MR. Critical experimental comparison between five techniques for the determination of interfacial tension in polymer blends: Model system of polystyrene/Polyamide-6. Macromolecules 2000; 33(21):8020-8034.

21. Maffettone PL, Minale M. Equation of change for ellipsoidal drops in viscous flow. J. Non-Newtonian Fluid Mechanics 1998; 78(2-3):227-241.

22. Abdel-Azim AAA, Atta AM, Farahat MS, Boutros WY. Determination of intrinsic viscosity of polymeric compounds through a single specific viscosity measurement. Polymer 1998; 39(26):6827-6833.

23. Chee KK. A critical evaluation of the single-point determination of intrinsic viscosity. J.Appl. Polym.Sci 1987; 34(3):891-899.

24. Borman WFH. Molecular weight-viscosity relationships for poly (1,4-butylene terephthalate). J. Appl.Polym. Sci. 1978; 22: 2119-2126.

25. Kamal MR, Lai-Fook R, Demarquette NR. Interfacial tension in polymer melts. Part II: Effects of temperature and molecular weight on interfacial tension. Polym. Eng. Sci. 1994; 34(24):1834-1839. 